\title{
A leaf bud technique for rapid propagation of cassava (Manihot esculenta Crantz)
}

\author{
Reizaluamar de Jesus Neves $^{1(\mathbb{D}}$, Leonardo Silva Souza ${ }^{1}$, Eder Jorge de Oliveira ${ }^{2 *}$ ([)
}

'Universidade Federal do Recôncavo da Bahia/Centro de Ciências Agrárias, Ambientais e Biológicas, R. Rui Barbosa, 710 - 44380-000 - Cruz das Almas, BA - Brasil.

2Embrapa Mandioca e Fruticultura, R. Embrapa, s/n44380-000 - Cruz das Almas, BA - Brasil.

*Corresponding author <eder.oliveira@embrapa.br>

Edited by: Lincoln Zotarelli

Received January 04, 2018

Accepted August 16, 2018
ABSTRACT: The slow rate of multiplication is one of the main constraints on the production of cassava (Manihot esculenta Crantz). This work aimed to evaluate the use of leaf buds for rapid propagation of cassava varieties. Leaf buds were excised from three cassava varieties (BRS Kiriris, 98150-06 and 9624-09) for plantlet generation. The experiment was completely randomized with a 5 (age of mother plant) $\times 3$ (position of the leaf buds on the stems) $\times 2$ (agrochemical treatments) factorial design. Data were collected on leaf sprouting percentage (Spro.Per), plantlet height (Plant.Hei) and total dry mass of plantlets (Dry.Mass.Plant). There was a difference between the three traits for most of the varieties, demonstrating significant effects on the agronomic attributes evaluated. Better agronomic performance (higher sprouting percentage, plantlet height and total dry mass) in plantlets was observed in leaf buds of: i) maturing plants up to six months old; ii) more herbaceous (upper) parts; and iii) plants treated with agrochemicals (fungicides and insecticides). Considering four-month-old plants, three annual cycles, and an $81 \%$ average sprouting, it would be possible to reach an annual multiplication rate of $1: 72$, which is much higher than that achieved by traditional methods using mature stem cuttings from 12-month-old plants (around 1:5). These results are important because they demonstrate the possibility of using cassava leaf buds to produce high-quality plantlets rapidly for greater multiplication and diffusion of new varieties and cultivation on a larger scale.

Keywords: sprouting, cuttings, alternative multiplication, asexual propagation

\section{Introduction}

Cassava (Manihot esculenta Crantz) is propagated from parts of the stem known as cuttings, especially in commercial plantations. The crop can also be propagated by seeds under natural conditions as well as artificial hybridization in breeding programs (Alves, 2002). However, the seedlings show a number of negative characteristics, such as slow development in the field, smaller size and less vigor when compared to plants derived from clonal propagation (Alves, 2002). Furthermore, vegetative propagation can result in a low multiplication rate (Aladele and Kuta, 2008). As a consequence, the replacement of landraces by improved varieties with better yield and resistance to disease remains major concern, and the rapid establishment of large areas for commercial exploitation is not easy.

Ukpe and Mustapha (2016) reported that the increase in cassava yield is limited by several factors, among them the scarcity of planting material. Therefore, it is essential to develop techniques that increase the multiplication rate associated with high phytosanitary quality (Vidal et al., 2015). In vitro micropropagation is a technique for producing planting material with high phytosanitary quality on a large scale in a short period (Aladele and Kuta, 2008), but the high cost of this technique is its main disadvantage (Ogero et al., 2010). On the other hand, an alternative technique of rapid multiplication was developed by Cock et al. (1976) using two bud cuttings, based on shoot induction in propagation chambers and subsequent rooting in water. However, it takes 8 to 12 months to obtain the first plantlets from this technique since the buds must be mature enough to generate new plants (Cock et al., 1976).
Thus, an alternative method is the use of leaf buds, which can allow for a considerable increase in cuttings from the mother plants. However, the leaf bud technique can be influenced by several factors, depending on the mother plant, often associated with physiological differences, or the presence of different carbohydrate concentrations along the stem (Hartmann et al., 2011). Therefore, the aim of this work was to evaluate the sprouting ability of leaf buds originating from different locations along the cassava stem at different stages of development of the mother plant, as well as the effect of agrochemicals on plantlet development.

\section{Materials and Methods}

The experiment was conducted in a randomized complete block design in a 5 (mother plant ages) $\times 3$ (locations of the leaf buds on the mother plant stem) $\times 2$ (agrochemical treatments) factorial scheme, with 4 replicates and 18 plants per plot.

\section{Plant material}

The experiment was carried out in Cruz das Almas, Bahia, Brazil (Latitude $12^{\circ} 40^{\prime} 19^{\prime \prime} \mathrm{S}$, Longitude $39^{\circ} 06^{\prime} 22^{\prime \prime} \mathrm{W}$, altitude $226 \mathrm{~m}$ ). The cassava variety BRS Kiriris, which is widely cultivated by farmers in the coastal part of the Brazilian northeastern region, as well as new clones 98150-06 and 9624-09 developed by the cassava breeding program of Embrapa Mandioca e Fruticultura, were selected. The $20 \mathrm{~cm}$ cuttings from these varieties were planted in the rainy season to provide the leaf buds needed to conduct the experiments. 


\section{Plantlet preparation and data collection}

The aboveground parts of the plants were collected early in the morning to ensure greater turgidity of the material (Hartmann et al., 2011) and then sent to the greenhouse to set up the experiments. Initially, the leaf blade was cut ( $1 / 3$ of the original size) using clean scissors, and the stems were placed in water containers to avoid leaf wilting. The leaf buds from different stem locations were identified (i.e., buds from the upper region - herbaceous part; buds from the middle region - intermediate part; and buds from the lower region - lignified part; Figure 1). Next, a " $\mathrm{V}$ " cut on the stems was made using a sterilized scalpel. The leaf bud cuttings were planted in $290 \mathrm{~cm}^{3}$ plastic tubes containing vermiculite and washed sand $(1: 1$ ratio) in the upper part of the tube (1/4 of the total volume). The substrate of the lower part of the plastic tube (3/4 of the total volume) was composed of vermiculite, soil and coconut fiber (1:2:1 ratio), $15 \mathrm{mg}$ of single superphosphate and $15 \mathrm{mg}$ of ammonium sulfate.

The cutting was performed at five different times: the first cutting was at 4 months after planting (4 MAP), the second at $6 \mathrm{MAP}$, the third at $8 \mathrm{MAP}$, the fourth at 10 MAP and the fifth at 12 MAP. Moreover, since the cutting process can cause injuries to cassava cuttings with subsequent direct exposure of this vegetative structure to the substrate, the effects of applying a fungicide and an insecticide to prevent damage to cuttings was also evaluated. The chemical treatment consisted of Cruiser (thiamethoxam $160 \mathrm{mg}$, manufactured in 2015) and Maxim Advanced (mefenoxam $7.6 \mathrm{mg}$, fludioxonil 9.5 $\mathrm{mg}$, and thiabendazole $57 \mathrm{mg}$, manufactured in 2015), diluted in $100 \mathrm{~mL}$ of distilled water. The leaf bud cuttings were submerged in this solution for $3 \mathrm{~min}$ and then planted in the plastic tubes. A control group was established without agrochemicals.
The leaf bud cuttings were maintained in a greenhouse with controlled humidity $(70 \pm 5 \%)$ and temperature $\left(28^{\circ} \mathrm{C} \pm 2{ }^{\circ} \mathrm{C}\right)$ for the shoot and root development. The plantlets were kept in the greenhouse for rooting induction until reaching approximately $10 \mathrm{~cm}$ in height, after which they were transferred to $50 \%$ shade for five days for later field transplanting.

The efficiency of this new method of cassava production by leaf buds was evaluated by the number of plants generated per treatment as well as by the following traits: sprouting percentage considering the portion of leaf buds that generated shoots; plantlet height measured in centimeters from the base to the apex of the shoot; and total dry mass of the plantlets obtained by the formula: total dry mass $=$ dry mass of the roots + dry mass of the shoots.

\section{Statistical analysis}

Before analyzing the data, we tested the basic assumptions for analysis of variance, i.e., the experimental errors normally distributed (Shapiro-Wilk test) and equal variances between treatments (Levene test). Next, an analysis of variance was performed in a triple factorial scheme, using the "ea2" function of the easyanova package (Arnhold, 2013) of the R software program (R Development Team, 2016). Finally, the means were compared by Tukey test $(p<0.05)$.

\section{Results}

\section{Effects of the age of mother plant, location on leaf bud and agrochemical treatment on plantlet development}

The ANOVA yielded a statistically significant effect $(p<0.01)$ for the age of mother plant, location on

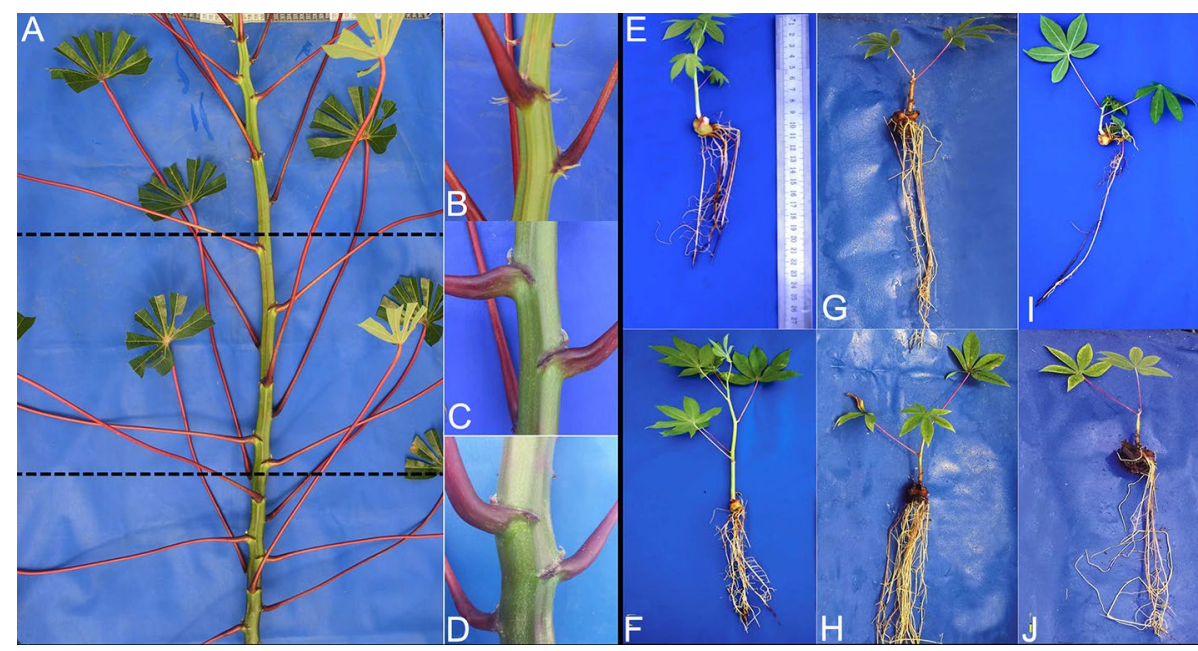

Figure 1 - The position of the leaf buds on the cassava stems from mother plants. A) overview of the aerial part; B) leaf buds of the upper plant position; C) leaf buds of the middle position; D) leaf buds of the lower position; E, G, and I) untreated plantlets from leaf buds of the upper, middle and lower positions of the untreated mother plants, respectively; $\mathrm{F}, \mathrm{H}$, and J) plantlets treated with agrochemicals from leaf buds of the upper, middle and lower position of the treated mother plants, respectively. 
leaf bud and agrochemical treatment in all the phenotypic traits and cassava varieties analyzed except for the sprouting percentage in clone 9624-09 (Table 1). The interaction age of the mother plant $\times$ position of the leaf buds was significant for all traits except for sprouting percentage in the BRS Kiriris variety. A similar situation was observed for the interaction of mother plant age $x$ agrochemical treatment, which was not significant for sprouting percentage in the BRS Kiriris and 98150-06 varieties. In contrast, the interaction between position of the leaf buds $\times$ agrochemical treatment was significant for plantlet height (BRS Kiriris and 9624-09) and total dry mass of plantlets (BRS Kiriris) (Table 1).

The age of the mother plant from which the stem was collected directly affected the sprouting percentage, plantlet height and total dry mass of plantlets, and in general the three cassava varieties had similar behavior for these traits (Table 2). For example, high sprouting percentage for the varieties BRS Kiriris (about $82 \%$ ), 98150-06 (80 to $85 \%$ ) and 9624-09 (78 to $90 \%$ ) were identified in plantlets from mother plants with 4 and 6 MAP. For plantlets from mother plants with $8 \mathrm{MAP}$, the sprouting percentage declined significantly in all cassava varieties, reaching around $30 \%$ in plantlets from mother plants collected at 12 MAP.

The average plantlet height from mother plants collected at 6 MAP was greater than the remaining stem harvest times for the three varieties reaching more than $9 \mathrm{~cm}$ in BRS Kiriris and 9624-09 and $13 \mathrm{~cm}$ in 98150-06 (Table 2). Similarly, the highest averages for the total dry mass trait were obtained from leaf buds with 6 MAP for three varieties (range of 0.83 to 1.05 g per plant) (Table 2 ). For most cassava varieties the plantlets growth from mother plants with more than 8 MAP were lower than from 4 and 6 MAP. This can mean lower quality plantlets since after 6 MAP there were reductions of around $60 \%$ in sprouting percentage, $50 \%$ in plantlet height and $70 \%$ in total dry mass.

Plantlets from leaf buds of the upper region of the mother plant had higher values for all the agronomic traits in the three cassava varieties, followed by the middle and lower positions (Table 3). The plantlets from leaf buds of the upper position of the mother plants had a $79 \%$ increase in plantlet height for BRS Kiriris and an increase of more than $30 \%$ for clones 98150-06 and 9624-09, compared with the lower position. Increases of $148 \%, 38 \%$, and $63 \%$ in total dry mass were identified for the varieties BRS Kiriris, 98150-06 and 9624-09, respectively, comparing the upper with the lower region of the mother plant.

The treatment of leaf buds with agrochemicals (fungicide and insecticide) increased by $15 \%$ in sprouting percentage in two varieties (BRS Kiriris and 9815006) (Table 4). In addition, plantlets from treated leaf

Table 1 - Analysis of variance of three traits for three varieties of cassava plantlets obtained from leaf buds, considering different positions on the stems, different ages of the mother plant and agrochemical treatment.

\begin{tabular}{|c|c|c|c|c|c|c|c|c|c|c|}
\hline \multirow{3}{*}{ Sources of variation } & \multirow{3}{*}{$\mathrm{DF}^{1}$} & \multicolumn{9}{|c|}{ Mean squares } \\
\hline & & \multicolumn{3}{|c|}{ Sprouting percentage } & \multicolumn{3}{|c|}{ Plantlet height } & \multicolumn{3}{|c|}{ Total dry mass of plantlets } \\
\hline & & BRS Kiriris & $98150-06$ & $9624-09$ & BRS Kiriris & $98150-06$ & $9624-09$ & BRS Kiriris & $98150-06$ & $9624-09$ \\
\hline & \multicolumn{4}{|c|}{$\%$} & \multicolumn{3}{|c|}{$\mathrm{c} \mathrm{cm}$} & \multicolumn{3}{|c|}{ g per plant } \\
\hline Block & 3 & 64.03 & 38.56 & 44.23 & 0.13 & 0.35 & 1.18 & 0.003 & 0.005 & 0.001 \\
\hline Age of mother plant (Age.Mo.Plant) & 4 & $10198.79^{*}$ * & $13153.53^{* *} 1$ & $13932.66^{* *}$ & $98.70^{* *}$ & $255.36^{\star *}$ & $487.96^{* *}$ & $1.33^{* *}$ & $2.16^{* *}$ & $1.57^{* *}$ \\
\hline Leaf bud position (Po.Leaf.Bud) & 2 & $1597.76^{* *}$ & $1163.09^{* *}$ & $957.79^{* *}$ & $214.02^{* *}$ & $65.45^{* *}$ & $86.48^{* *}$ & $2.77^{* *}$ & $0.60^{* *}$ & $0.67^{* *}$ \\
\hline Agrochemical treatment (Agro.Tre) & 1 & $2623.32^{* *}$ & $2231.02^{* *}$ & 65.91 & $71.95^{\star *}$ & $58.33^{* *}$ & $48.16^{* *}$ & $0.68^{* *}$ & $0.54^{\star *}$ & $0.52^{* *}$ \\
\hline Age.Mo.Plant $\times$ Po.Leaf.Bud & 8 & 66.68 & $475.20^{* *}$ & $217.34^{* *}$ & $19.15^{\star *}$ & $121.85^{\star *}$ & $647.81^{* *}$ & $0.36^{* *}$ & $1.57^{\star \star *}$ & $1.42^{* *}$ \\
\hline Age.Mo.Plant $\times$ Agro.Tre & 4 & 99.94 & 116.35 & $629.15^{* *}$ & $7.94^{* *}$ & $3.83^{* *}$ & $23.56^{* *}$ & $0.06^{* *}$ & $0.05^{* *}$ & $0.07^{* *}$ \\
\hline Po.Leaf.Bud $\times$ Agro.Tre & 2 & 63.50 & 46.63 & 99.76 & $2.30^{* *}$ & 0.07 & $4.21^{* *}$ & $0.11^{* *}$ & 0.00 & 0.00 \\
\hline Residual & 87 & 28.56 & 80.03 & 34.12 & 0.21 & 0.41 & 0.10 & 0.001 & 0.002 & 0.001 \\
\hline Coefficient of variation - CV (\%) & & 8.35 & 14.37 & 9.32 & 5.96 & 7.38 & 4.54 & 6.73 & 8.11 & 6.48 \\
\hline
\end{tabular}

${ }^{1} \mathrm{DF}=$ degrees of freedom; ${ }^{\star \star},{ }^{\star \star \star}{ }^{*}$ significant at $1 \%$ and $0.1 \%$ probability by the F-test, respectively.

Table 2 - Mean sprouting percentage, plantlet height and total dry matter of leaf bud plantlets from three cassava varieties (BRS Kiriris, $98150-06$ and 9624-09), collected at five mother plant ages.

\begin{tabular}{|c|c|c|c|c|c|c|c|c|c|}
\hline \multirow{2}{*}{ Age of the mother plant } & \multicolumn{3}{|c|}{ Sprouting percentage } & \multicolumn{3}{|c|}{ Plantlet height } & \multicolumn{3}{|c|}{ Total dry mass of plantlets } \\
\hline & BRS Kiriris & $98150-06$ & 9624-09 & BRS Kiriris & $98150-06$ & 9624-09 & BRS Kiriris & $98150-06$ & $9624-09$ \\
\hline & & $\%$ & 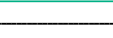 & & $-\mathrm{cm}-$ & 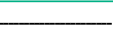 & 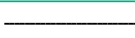 & g per plant & 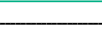 \\
\hline 4 & $82.63 \mathrm{a}$ & $80.32 \mathrm{a}$ & $78.47 \mathrm{~b}$ & $8.37 \mathrm{~b}$ & $9.66 b$ & $8.86 b$ & $0.67 c$ & $0.76 \mathrm{~b}$ & $0.77 \mathrm{~b}$ \\
\hline 6 & $82.40 \mathrm{a}$ & $84.52 \mathrm{a}$ & $90.04 a$ & $9.29 a$ & $13.01 \mathrm{a}$ & $9.79 a$ & $0.83 a$ & $1.05 \mathrm{a}$ & $0.84 a$ \\
\hline 8 & $65.51 b$ & $70.37 \mathrm{~b}$ & $67.36 \mathrm{c}$ & $9.44 \mathrm{a}$ & $9.61 \mathrm{~b}$ & $7.31 \mathrm{c}$ & $0.72 b$ & $0.70 \mathrm{c}$ & $0.45 c$ \\
\hline 10 & $56.48 c$ & $46.29 c$ & $47.68 d$ & $6.68 c$ & $6.75 c$ & $6.08 d$ & $0.43 d$ & $0.49 d$ & $0.38 d$ \\
\hline 12 & $33.10 \mathrm{~d}$ & $29.86 d$ & $29.86 \mathrm{e}$ & $4.64 \mathrm{~d}$ & $4.41 d$ & $4.01 \mathrm{e}$ & $0.25 \mathrm{e}$ & $0.25 \mathrm{e}$ & $0.24 \mathrm{e}$ \\
\hline
\end{tabular}

Means followed by the same letter in the column for each trait and variety do not differ by the Tukey test $(p<0.05)$. 
Table 3 - Mean sprouting percentage, plantlet height and total dry matter of leaf bud plantlets from three cassava varieties (BRS Kiriris, 98150-06 and 9624-09), collected from different positions on the stems of the mother plants.

\begin{tabular}{|c|c|c|c|c|c|c|c|c|c|}
\hline \multirow{2}{*}{ Po.Leaf.Bud } & \multicolumn{3}{|c|}{ Sprouting percentage } & \multicolumn{3}{|c|}{ Plantlet height } & \multicolumn{3}{|c|}{ Total dry mass of plantlets } \\
\hline & BRS Kiriris & $98150-06$ & 9624-09 & BRS Kiriris & $98150-06$ & 9624-09 & BRS Kiriris & 98150-06 & $9624-09$ \\
\hline & & $\%$ & & & $-\mathrm{cm}-$ & & & g per plant & \\
\hline U & 70.27 a & $68.05 a$ & $67.22 \mathrm{a}$ & $10.23 a$ & $10.14 a$ & $8.39 a$ & $0.87 a$ & $0.79 a$ & $0.67 a$ \\
\hline M & $64.16 b$ & $61.38 b$ & $63.33 b$ & $7.13 b$ & $8.19 b$ & $6.83 \mathrm{~b}$ & $0.52 b$ & $0.59 b$ & $0.53 b$ \\
\hline L & $57.63 c$ & $57.38 b$ & $57.50 \mathrm{c}$ & $5.70 \mathrm{c}$ & $7.73 c$ & $6.41 \mathrm{c}$ & $0.35 c$ & $0.57 b$ & $0.41 \mathrm{c}$ \\
\hline
\end{tabular}

Po.Leaf.Bud = positions on the stems of the mother plants (upper $=\mathrm{U}$; middle $=\mathrm{M}$ and lower position $=\mathrm{L}$ ). Means followed by the same letter in the column for each trait and variety do not differ by the Tukey test $(p<0.05)$.

Table 4 - Mean of sprouting percentage, plantlet height and total dry matter of leaf bud plantlets from three cassava varieties (BRS Kiriris, 9815006 and 9624-09), treated or not with agrochemicals.

\begin{tabular}{|c|c|c|c|c|c|c|c|c|c|}
\hline \multirow{2}{*}{ Agrochemicals } & \multicolumn{3}{|c|}{ Sprouting percentage } & \multicolumn{3}{|c|}{ Plantlet height } & \multicolumn{3}{|c|}{ Total dry mass of plantlets } \\
\hline & BRS Kiriris & $98150-06$ & 9624-09 & BRS Kiriris & $98150-06$ & 9624-09 & BRS Kiriris & $98150-06$ & $9624-09$ \\
\hline & \multicolumn{3}{|c|}{ 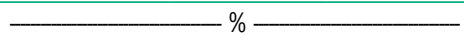 } & & $-\mathrm{cm}-$ & 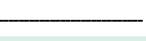 & \multicolumn{3}{|c|}{$\longrightarrow$ g per plant } \\
\hline Untreated & $59.35 b$ & $57.96 \mathrm{~b}$ & $63.42 \mathrm{a}$ & $6.91 b$ & $7.99 \mathrm{~b}$ & $6.57 \mathrm{~b}$ & $0.50 \mathrm{~b}$ & $0.58 \mathrm{~b}$ & $0.47 b$ \\
\hline Treated & $68.70 \mathrm{a}$ & 66.58 a & $61.94 \mathrm{a}$ & $8.46 \mathrm{a}$ & $9.39 \mathrm{a}$ & $7.85 \mathrm{a}$ & $0.65 \mathrm{a}$ & $0.72 \mathrm{a}$ & $0.60 \mathrm{a}$ \\
\hline
\end{tabular}

Means followed by the same letter in the column for each trait and variety do not differ by the Tukey test $(p<0.05)$.

buds showed greater growth compared to plantlets from untreated leaf buds, ranging from 18 to $22 \%$ for the 98150-06 and BRS Kiriris, respectively. A similar situation was observed for total dry mass of all the varieties, in which the superiority of the plantlets treated with agrochemicals ranged from 24 to $30 \%$ for the varieties 98150-06 and BRS Kiriris, respectively (Table 4).

\section{Effect of the age of the mother plant on the position of the leaf buds}

Depending on the age of the mother plant, the vigor and sprouting percentage of the plantlets may be affected by the position of the leaf buds on the stem. For clones 98150-06 and 9624-09, plantlets with higher sprouting percentage, plantlet height and total dry mass were formed by leaf buds excised from the upper position of the mother plant at 6 MAP (Table 5). The sprouting percentage of these varieties did not yield a significant difference between the different positions on the mother plants at 4 MAP. On the other hand, for clones 98150-06 and 9624-09, the leaf buds collected at 4 MAP on the lower position of the mother plants produced plantlets with greater vigor considering the traits' plantlet height $(>13 \mathrm{~cm})$ and total dry mass $(>1.39 \mathrm{~g}$ per plant).

For the BRS Kiriris variety, the highest sprouting percentages were obtained when using leaf buds from mother plants with $6 \mathrm{MAP}$, regardless of their location on the stem (Table 5). In contrast, plantlets with greater height were obtained from leaf buds from the upper plant region with 6 and 8 MAP (13.05 to $13.42 \mathrm{~cm}$ ), while for total dry mass, the best results were obtained from plantlets from leaf buds of the upper plant region collected at $6 \mathrm{MAP}$. From $8 \mathrm{MAP}$, the plantlets presented a sharp decrease in sprouting percentage, plantlet height and total dry mass.

\section{Discussion}

In Brazil recommended cassava varieties are widely adopted by farmers but the area planted with improved varieties increased slowly due to the typically low multiplication rate of this crop. Therefore, the development of rapid multiplication technologies can bring several opportunities to multiply breeder and certified seeds of new varieties rapidly for easy availability to farmers. In this study we described the technique of rapid multiplication of cassava using leaf buds as a viable strategy to be incorporated into the cassava seeds system. The main results showed that in general, plantlets from leaf buds excised from mother plants with 6 MAP showed the highest sprouting percentage, height and total dry mass, resulting in more vigorous cassava plantlets. According to Alves (2002), cassava has higher metabolic activity and greater leaf and stem growth rate between 3 and $6 \mathrm{MAP}$, and thus greater vegetative growth in this period. The highest sprout quality of cassava plantlets from leaf buds was obtained from herbaceous (apical) stems, with an increase in sprout and plantlet quality due to the lower degree of tissue lignification. These results are similar to those observed by Bona et al. (2012), who reported that apical cuttings, with a lower degree of lignification, conferred ideal physiological conditions such as the presence of auxins and essential substances for greater rooting of plantlets of Lavandula dentata L.

In general, plantlets with high vigor were obtained from buds from the mother plants' upper parts at 6 MAP. The plantlets from the most lignified parts of the plant showed less development of the root system resulting in the production of lower quality plantlets. Moreover, regardless of these exceptions, there was a strong tendency for lower sprouting percentage, plantlet height and total dry mass from the top to the bottom 


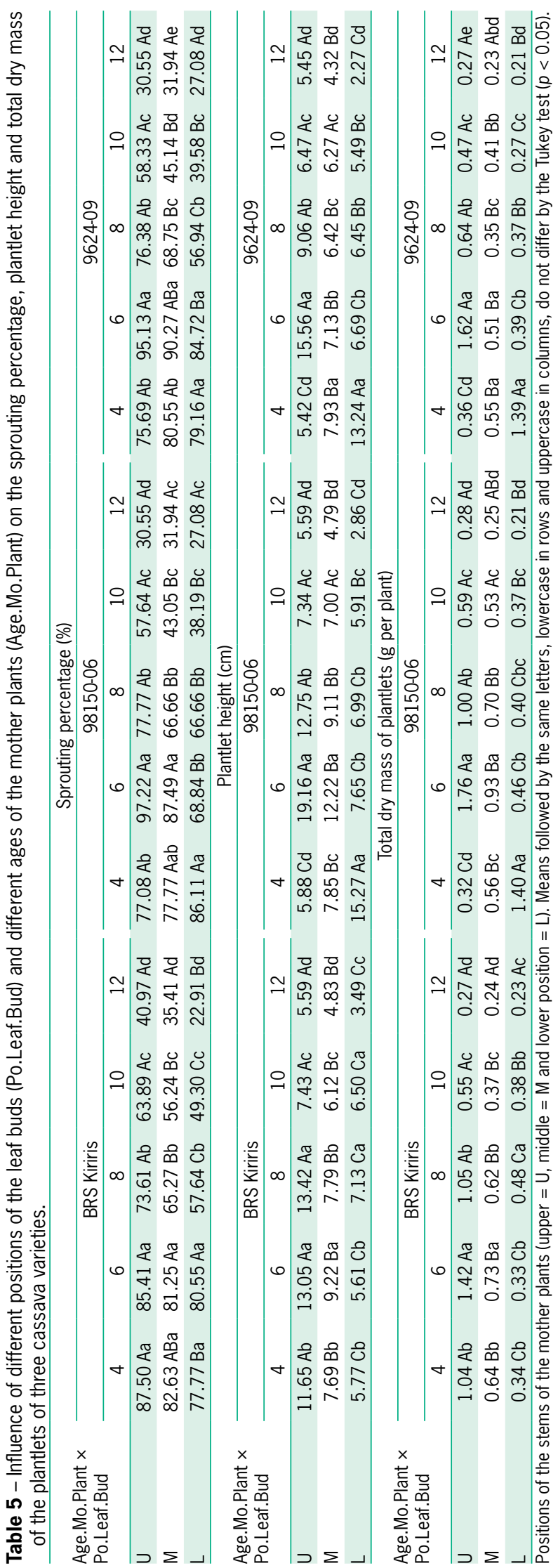

parts of the cassava stems. Species of asexual propagation can present different responses to rooting, depending on the cutting type (Hartmann et al., 2011).

Another factor to be taken into account when considering cassava plantlet production by leaf buds is the varieties to be propagated since there may be a differential in responses because the period of the stems' maturation varies according to the genetic material, and leads to different responses in the plantlets' rooting. We observed that different cassava varieties that were planted under the same conditions presented different levels of development and physiological maturation. In the case of clone 98150-06, the leaf buds from the lower part of the stem were more developed than the leaf buds of the BRS Kiriris variety from the same stem position.

The positive effect on the cassava vigor promoted by the treatment with agrochemicals can be explained by the ability of certain of the products to promote the socalled phytotonic effect in addition to the protective effect which generally activates physiological reactions in plants that result in an increase in germination and vigor (Horii et al., 2007). One of these products is the insecticide thiamethoxam, from the group of neonicotinoids (Maienfisch et al., 2001), which, depending on the species, can act as a bioactivator affecting the expression of proteins and positively modifying the plant metabolism and morphology.

Some fungicides can also have positive physiological effects on plants and promote better germination and seed vigor (Matos et al., 2013). The use of thiamethoxam, in addition to the fungicides metalaxyl- $M$, thiabendazole and fludioxonil, for the development of cassava plantlets has been examined, and leaf bud analysis suggests that the use of these agrochemicals has more than a protective effect on the plantlets (Matos et al., 2013). The treatment of leaf buds with agrochemicals was an important factor for the production of high-quality cassava plantlets since it resulted in a higher percentage of plantlets, higher biomass and better development of plantlets, regardless of the leaf buds' position on the mother plant. Therefore, the significant differences observed in the three agronomic traits demonstrated that the chemical treatment should be performed on a large-scale production of plantlets from leaf buds considering the greater vigor and better rooting of the treated plantlets.

The results showed that even when using agrochemical treatment the average trait values of plantlets from the leaf buds of the middle and lower regions of the stems did not exceed the corresponding means of the plantlets derived from the upper region for height and total dry mass traits. On the other hand, in rapid propagation of cassava such as by the leaf bud technique, the use of buds from the whole mother plant can increase the multiplication rate. This, associated with the use of agrochemicals, resulted in higher sprouting percentages $(66 \%$ and $60 \%$ in treated and untreated leaf buds), greater plant height (8.6 $\mathrm{cm}$ and $7.2 \mathrm{~cm}$ in treated and untreated leaf buds), and higher dry matter content $(0.7 \mathrm{~g}$ per plant and $0.5 \mathrm{~g}$ per plant in both treated and untreated leaf buds). 
An important aspect of choosing a clonal multiplication method is the time required to achieve plant production goals. This is especially important for cassava where annual rates of propagation are very low (1:5 to $1: 10$, depending on the variety). Therefore, any method that can promote improvements of these multiplication rates will certainly have important impacts, whether in the dissemination of a new variety or the rapid establishment of large plantations to meet industrial demands. Regardless of the variety and leaf bud position on the stems the sprouting percentage of the leaf buds with 4 and 6 MAP was greater than $82 \%$ compared to approximately $50 \%$ for the leaf buds from mother plants older than 8 MAP. This same observation applies to plantlet height $(8.83,11.34$ and $9.33 \mathrm{~cm}$, respectively, for the BRS Kiriris, 98150-06 and 9624-09 varieties up to 6 MAP compared to 6.92, 9.93, and $5.80 \mathrm{~cm}$, respectively, for leaf buds above $8 \mathrm{MAP}$ ) and dry matter content $(0.75,0.91$, and $0.80 \mathrm{~g}$ per plant, respectively, for the BRS Kiriris, 98150-06 and 9624-09 up to $6 \mathrm{MAP}$ in comparison to $0.47,0.48$, and $0.36 \mathrm{~g}$ per plant, respectively, for the leaf buds from mother plants older than 8 MAP).

Although the number of leaf buds according to harvest time was not counted it is possible to realistically speculate that about 30 leaf buds were produced per plant up to 6 MAP. Therefore, considering plants with 4 $\mathrm{MAP}$, three annual cycles, and an average sprouting rate of $81 \%$, it would be possible to reach an annual multiplication rate of $1: 72$. With mother plants having 6 MAP and average sprouting of $86 \%$, it would be possible to reach an annual multiplication rate of 1:51. Regardless of the method, the multiplication rates attained by using the leaf buds were much higher than that obtained by the traditional method of multiplication (stem cuttings). However, other technical issues should be taken into account when adopting this kind of multiplication, which is more costly since it requires investments in greenhouses with humidity control as well as greater labor for plantlet production.

In conclusion, cassava plantlet production based on leaf buds is an auxiliary strategy for increasing the multiplication rate of cassava a few dozen times, in comparison to conventional multiplication by stem cuttings. Moreover, the high sprouting percentage and greater vigor of cassava plantlets can be obtained using leaf buds from the upper region of mother plants up to 6 MAP. Another important observation is that the bioactivating effect of some agrochemicals was very effective in increasing the sprouting rate and vigor of the plantlets derived from the herbaceous cuttings collected in the juvenile phases of the mother plants, which contributed to increasing growth and plantlet rooting.

\section{Acknowledgments}

The authors thank the Fundação de Amparo à Pesquisa do Estado da Bahia (FAPESB), Coordenação de Aperfeiçoamento de Pessoal de Nível Superior (CAPES), Conselho Nacional de Desenvolvimento Científico e Tecnológico ( $\mathrm{CNPq}$ ) for the financial assistance and scholarship support. We also thank the Syngenta Foundation for Sustainable Agriculture and the Bill \& Melinda Gates Foundation for additional support, through the MandiPlus project.

\section{Authors' Contributions}

Conceptualization: Neves, R.J.; Oliveira, E.J. Data acquisition: Neves, R.J.; Souza, L.S. Data analysis: Neves, R.J.; Oliveira, E.J. Writing and editing: Neves, R.J.; Souza, L.S.; Oliveira, E.J.

\section{References}

Aladele, S.E.; Kuta, D.D. 2008. Environmental and genotypic effects on the growth rate of in vitro cassava plantlet (Manihot esculenta). African Journal of Biotechnology 7: 381-385.

Alves, A.A.C. 2002. Cassava botany and physiology. p. 67-89. In: Hillocks, R.J.; Thresh, J.M.; Bellotti, A.C., eds. Cassava: biology, production and utilization. CABI Wallingford, UK.

Arnhold, E. 2013. Package in the R environment for analysis of variance and complementary analyses. Brazilian Journal of Veterinary Research and Animal Science 50: 488-492.

Bona, C.M.; Biasetto, I.R.; Masetto, M.; Deschamps, C.; Biasi. L.A. 2012. Influence of cutting type and size on rooting of Lavandula dentata L. Revista Brasileira de Plantas Medicinais 14: 8-11.

Cock, J.H.; Wholey, D.; Lozano, J.C.; Toro, J.C. 1976. Rapid cassava propagation system. CIAT, Cali, Colombia. (Series ES20) (in Spanish, with abstract in English).

Hartmann, H.T.; Kester, D.E.; Davies Junior, F.T.; Geneve, R.L. 2011. Plant Propagation: Principles and Practices. 8ed. Pearson, Englewood Cliffs, NJ, USA.

Horii, P.M.; McCue, P.; Shetty, K. 2007. Enhancement of seed vigor following insecticide and phenolic elicitor treatment. Bioresource Technology 98: 623-632.

Maienfisch, P.; Angst, M.; Brandl, F.; Fischer, W.; Hofer, D.; Kayser, H.; Kobel, W.; Rindlisbacher, A.; Senn, R.; Steinemann, A.; Widmer, H. 2001. Chemistry and biology of thiamethoxam: a second generation neonicotinoid. Pest Management Science 57: 906-913.

Matos, C.D.S.M.D.; Barrocas, E.N.; Machado, J.D.C.; Alves, F.C. 2013. Health and physiological quality of corn seeds treated with fungicides and assessed during storage. Journal of Seed Science 35: 10-16.

Ogero, K.; Gitonga, N.M.; Ombori, O.; Ngugi, M. 2010. Cassava production and limitation of propagation through tissue culture: contributions of agricultural sciences towards achieving the Millenium Development Goals. FaCT, London, UK.

Ukpe, E.; Mustapha, S.M.F.D.S. 2016. Agricultural knowledge management: a case study of Nigeria cassava production process. Journal of Agricultural Science and Research 3: 11-16.

Vidal, A.M.; Vieira, L.J.; Ferreira, C.F.; Souza, F.V.D.; Souza, A.S.; Ledo, C.A.S. 2015. Genetic fidelity and variability of micropropagated cassava plants (Manihot esculenta Crantz) evaluated using ISSR markers. Genetics and Molecular Research 14: 7759-7770. 